Supporting Information

\title{
Design and Synthesis of Potent Cystine-Free Cyclic Hexapeptide Agonists at the Human Urotensin Receptor
}

\author{
Shane Foister, ${ }^{*}$ Laurie L. Taylor, ${ }^{\dagger}$ Jin-Jye Feng, ${ }^{\ddagger}$ Wen-Long Chen, ${ }^{\ddagger}$ Atsui Lin,${ }^{\ddagger}$ Fong-Chi \\ Cheng, ${ }^{\ddagger}$ Amos B. Smith III, ${ }^{*}$ Ralph Hirschmann ${ }^{*}$ \\ *Department of Chemistry, University of Pennsylvania, Philadelphia, PA, 19104, ${ }^{\dagger}$ MDS Pharma Services, \\ Bothell, WA 98021, ${ }^{\ddagger}$ MS Pharma Services, Taipei, Taiwan
}


Materials and Methods: All solvents were reagent grade. Methanol, dichloromethane, acetonitrile, water, hexanes, ethyl ether, and trifluoroacetic acid were obtained from Fischer Scientific (Pittsburg, PA). N-methyl pyrrolidinone (NMP) was obtained from Advanced ChemTech (Louisville, KY). Triethylsilane, piperidine, and N,Ndiisopropylethylamine (DIEA), and O-(7-Azabenzotriazol-1-yl-N,N,N,Ntetramethyluronium hexafluorophosphate (HATU) were purchased from Aldrich (Milwaukee, WI). All N- $\alpha$-Fmoc-protected amino acids were of the L-configuration and were obtained from NovaBiochem (San Diego, CA), Advanced ChemTech (Louisville, KY), or Bachem Science (King of Prussia, PA). 2-chlorotrityl chloride resin, 1\% crosslinked with divinyl benzene, was obtained from NovaBiochem (San Diego, CA). 1hydroxybenzotriazole (HOBt) and benzotriazole-1-yl-oxy-tris-pyrrolidino-phosphonium hexafluorophosphate (PyBOP) were purchased from NovaBiochem (San Diego, CA) or Bachem Science (King of Prussia, PA).

The synthesis of linear peptide precursors was achieved manually using standard Fmoc-based techniques in conjunction with 2-chlorotrityl chloride resin. Loading of the first amino acid residue onto the solid support was achieved by adding a $0.5 \mathrm{M}$ solution of the appropriate $\mathrm{N}-\alpha-\mathrm{Fmoc}$ amino acid (2 equiv) and DIEA (4 equiv) in dichloromethane to the resin. The resulting slurry was agitated for 4 hours and filtered. The resin was then washed with dichloromethane and NMP. Removal of the N- $\alpha$-Fmoc group was accomplished by treating the resin with a $20 \%$ solution of piperidine in NMP (v:v) for 10 minutes. The resin was then washed thoroughly with NMP and dichloromethane. Acylation of support-bound amines was achieved by dissolving the appropriate $\mathrm{N}-\alpha$-Fmoc amino acid (3 equiv), PyBOP (3 equiv), HOBt ( 3 equiv), and DIEA (6 equiv) in NMP to a final concentration of $0.3-0.5 \mathrm{M}$. This solution was then added to the resin and the resulting slurry was agitated for 3 hours. The resin was then washed with NMP, methanol, and dichloromethane. The progress of acylation was qualitatively monitored by Kaiser test and coupling reactions were repeated when necessary.

Peptides were purified using a Waters preparative HPLC system with reversed phase columns (Varian Dynamax Microsorb $\mathrm{C}_{18}$ or Agilent Zorbax $\mathrm{C}_{8}$ ). The purity of peptides was then determined by analytical HPLC on the same stationary phases. The mobile phases employed were aqueous $0.1 \%$ TFA and acetonitrile. Peptides were eluted with a linear gradient of $0-100 \%$ acetonitrile over 15 minutes, using a flow rate of 10.0 $\mathrm{mL} / \mathrm{min}$. for preparative runs and $1.0 \mathrm{~mL} / \mathrm{min}$. in analytical runs. The $\mathrm{UV}$ absorbance at $230 \mathrm{~nm}$ and $280 \mathrm{~nm}$ was monitored throughout the course of HPLC runs. The identity of peptides was verified by ESI-MS. Pure peptides were lyophilized to white solids prior to their use in biochemical assays.

Different cyclization strategies were employed in the synthesis of disulfidebridged peptide 2 and lactam-bridged congeners $8 \mathrm{a}, 8 \mathrm{~b}, 9, \mathbf{1 0}$, and 11. Compound 2 was prepared by cyclization of a fully deprotected linear precursor obtained by cleaving the 2chlorotrityl resin with strong acid. The support-bound precursor for peptide 2, FmocCys(Trt)-Phe-Trp-Lys(Boc)-Tyr(O- $t$ Bu)-Cys(Trt)-R where $\mathrm{R}$ denotes 2-chlorotrityl resin, was elaborated using the protocols described above. The terminal $\mathrm{N}-\alpha$-Fmoc group was 
removed by treatment with a $20 \%$ solution of piperidine in NMP and the resin was washed thoroughly with dichoromethane. The resin was then shaken in a 1:1 (v:v) solution of TFA and dichloromethane containing $0.1 \%$ triethylsilane by volume $(5 \mathrm{~mL} / 50$ $\mathrm{mg}$ resin) for 20 minutes. The resin slurry was filtered and the above cleavage protocol was repeated two additional times. The cleavage solutions were combined and concentrated in vacuo. The resulting oil was dissolved in dichloromethane $(2 \mathrm{~mL})$ and cold ethyl ether $(18 \mathrm{~mL})$ was added to yield a white suspension. The white precipitate was collected by centrifugation and dissolved in a 1:1:0.1 (v:v:v) solution of trifluoroethanol, water, and $0.05 \mathrm{M}\left(\mathrm{NH}_{4}\right)_{2} \mathrm{CO}_{3}$ at a concentration of $0.5 \mathrm{mg} / \mathrm{mL}$. This solution was stirred while exposed to ambient conditions for 2 days. The crude reaction mixture was then concentrated and purified by preparative HPLC.

(2) c[Cys-Phe-Trp-Lys-Tyr-Cys] was prepared from H-Cys-Phe-Trp-Lys-Tyr-Cys-OH using the methods detailed above in $21 \%$ yield after HPLC, relative to resin. $\mathrm{R}_{\mathrm{f}}=16.2$ minutes. ESI-MS m/z (observed) $=847.3265 ;[\mathrm{M}+\mathrm{H}]^{+}\left(\right.$calculated for $\left.\mathrm{C}_{41} \mathrm{H}_{51} \mathrm{~N}_{8} \mathrm{O}_{8} \mathrm{~S}_{2}\right)=$ 847.3271 .

Lactam-bridged peptides 8-11 were prepared from sidechain-protected linear amino acids generated by cleavage of 2-chlorotrityl resin with dilute acid. Following elaboration of the desired linear peptide sequences, according to the general solid phase protocol above, the $\mathrm{N}-\alpha-\mathrm{Fmoc}$ protecting groups were cleaved with $20 \%$ piperidine in NMP and the resins were washed thoroughly with dichloromethane. The resins were then treated with a solution of $0.5 \%$ TFA in dichloromethane with $0.1 \%$ triethylsilane (5 $\mathrm{mL} / 50 \mathrm{mg}$ resin) for 20 minutes at room temperature. The resin slurries were then filtered and the above cleavage protocol was repeated two additional times. The combined cleavage solutions were concentrated in vacuo and the resulting oil was dissolved in cold methanol $(2 \mathrm{~mL})$. Cold water $(18 \mathrm{~mL})$ was then added and the resulting suspensions were filtered. The obtained solids were dried under high vacuum overnight and used directly in cyclization reactions as follows. The crude linear peptides were dissolved in 1:1 (v:v) solutions of acetonitrile and dichloromethane $(1 \mathrm{mg} / \mathrm{mL})$ with diisopropylethylamine (20 equiv). Powdered $4 \AA$ molecular sieves $(50 \mathrm{mg}$ ) and HATU (1.5 equiv) were then added and the resulting mixtures were stirred under inert atmosphere in an ice water bath. After 2 hours, the mixtures were allowed to warm to ambient temperature and stirred for an additional 4 days. The crude mixtures were filtered over celite and concentrated in vacuo. The resulting oily residues were dissolved in dichloromethane and washed with $0.1 \mathrm{M}$ citric acid, water, and saturated sodium bicarbonate. The organic phases were then concentrated. The crude residues were then dissolved in 50\% TFA in dichloromethane with $0.1 \%$ triethylsilane. The resulting solutions were stirred for 20 minutes and concentrated to pale yellow oils. The oils were then dissolved in acetonitrile and purified by preparative HPLC. The identity and purity of purified products were determined by ESI-MS and analytical HPLC, respectively. The above protocol was used to prepare the cyclic peptides below from the linear precursors indicated.

(8a) c[Phe-NMeAla-Ala-Tyr-Lys-Trp] was prepared from H-Trp-Lys(Boc)-Tyr(OtBu)Ala-NMeAla-Phe-OH using the methods detailed above in $11 \%$ yield after HPLC, 
relative to resin. $\mathrm{R}_{\mathrm{f}}=15.3$ minutes. ESI-MS m/z (observed) $=781.4040 ;[\mathrm{M}+\mathrm{H}]^{+}$ (calculated for $\mathrm{C}_{42} \mathrm{H}_{53} \mathrm{~N}_{8} \mathrm{O}_{7}$ ) $=781.4037$.

(8b) c[Phe-Pro-Ala-Tyr-Lys-Trp] was prepared from H-Trp-Lys(Boc)-Tyr(OtBu)-AlaPro-Phe-OH using the methods detailed above in $17 \%$ yield after HPLC, relative to resin. $\mathrm{R}_{\mathrm{f}}=16.4$ minutes. ESI-MS m/z (observed) $=793.4032 ;[\mathrm{M}+\mathrm{H}]^{+}$(calculated for $\left.\mathrm{C}_{43} \mathrm{H}_{53} \mathrm{~N}_{8} \mathrm{O}_{7}\right)=793.4037$.

(9) c[Phe-Ala-Ala-Tyr-Lys-Trp] was prepared from H-Trp-Lys(Boc)-Tyr(OtBu)-AlaAla-Phe-OH using the methods detailed above in $14 \%$ yield after HPLC, relative to resin. $\mathrm{R}_{\mathrm{f}}=14.8$ minutes. ESI-MS m/z (observed) $=767.3885 ;[\mathrm{M}+\mathrm{H}]^{+}$(calculated for $\left.\mathrm{C}_{41} \mathrm{H}_{51} \mathrm{~N}_{8} \mathrm{O}_{7}\right)=767.3881 .{ }^{1} \mathrm{H}$ NMR $\left(500 \mathrm{MHz}, \mathrm{D}_{2} \mathrm{O} / \mathrm{H}_{2} \mathrm{O}\right) \delta 7.6(1 \mathrm{H}), 7.48(1 \mathrm{H}), 7.22$ $(7 \mathrm{H}), 7.19(5 \mathrm{H}), 6.8(2 \mathrm{H}), 4.52(1 \mathrm{H}), 4.31(1 \mathrm{H}), 4.15(1 \mathrm{H}), 3.91(1 \mathrm{H}), 3.5(1 \mathrm{H}), 3.4(1 \mathrm{H})$, $3.31(3 \mathrm{H}), 3.12(1 \mathrm{H}), 2.9(1 \mathrm{H}), 2.73(2 \mathrm{H}), 1.46(5 \mathrm{H}), 1.3(3 \mathrm{H}), 1.19(3 \mathrm{H}), 0.6(1 \mathrm{H}), 0.3$ $(1 \mathrm{H})$.

(10) c[Phe-Glu-Ala-Tyr-Lys-Trp] was prepared from H-Trp-Lys(Boc)-Tyr(OtBu)-Ala$\mathrm{Glu}(\mathrm{OtBu})-\mathrm{Phe}-\mathrm{OH}$ using the methods detailed above in $10 \%$ yield after HPLC, relative to resin. $\mathrm{R}_{\mathrm{f}}=14.5$ minutes. ESI-MS m/z (observed) $=825.3940 ;[\mathrm{M}+\mathrm{H}]^{+}$(calculated for $\left.\mathrm{C}_{43} \mathrm{H}_{53} \mathrm{~N}_{8} \mathrm{O}_{9}\right)=825.3936$.

(11) c[Phe-Ala-Ala-2Nal-Lys-Trp] was prepared from H-Trp-Lys(Boc)-2Nal-Ala-AlaPhe-OH using the methods detailed above in $13 \%$ yield after HPLC, relative to resin. $\mathrm{R}_{\mathrm{f}}$ $=15.5$ minutes. ESI-MS m/z (observed) $=801.4090 ;[\mathrm{M}+\mathrm{H}]^{+}$(calculated for $\left.\mathrm{C}_{45} \mathrm{H}_{53} \mathrm{~N}_{8} \mathrm{O}_{6}\right)=801.4088 .{ }^{1} \mathrm{H}$ NMR $\left(500 \mathrm{MHz}, \mathrm{D}_{2} \mathrm{O} / \mathrm{H}_{2} \mathrm{O}\right) \delta 7.98(2 \mathrm{H}), 7.93(2 \mathrm{H}), 7.76$ $(1 \mathrm{H}), 7.61(6 \mathrm{H}), 7.49(2 \mathrm{H}), 7.36(4 \mathrm{H}), 7.29(4 \mathrm{H}), 7.19(2 \mathrm{H}), 4.38(2 \mathrm{H}), 4.17(2 \mathrm{H}), 3.82$ $(1 \mathrm{H}), 3.59(1 \mathrm{H}), 3.45(2 \mathrm{H}), 3.31(2 \mathrm{H}), 3.24(2 \mathrm{H}), 2.85(1 \mathrm{H}), 2.2(2 \mathrm{H}), 1.9(2 \mathrm{H}), 1.42$ $(2 \mathrm{H}), 1.3(2 \mathrm{H}), 1.1(3 \mathrm{H}), 0.5(1 \mathrm{H}), 0.36(1 \mathrm{H})$.

$\alpha$-chymotrypsin, type VII from bovine pancreas, was obtained from Sigma (EC 3.4.21.1) and used as received. A fresh stock solution of this enzyme $(1 \mathrm{mg} / \mathrm{mL})$ was prepared prior to each set of digestion experiments. Digestions were run in phosphate buffer ( $\mathrm{pH}$ 7) with enzyme and substrate concentrations from $0.2-0.5 \mathrm{mg} / \mathrm{mL}$. Timecourse experiments were performed by diluting aliquots from digestion reactions with methanol and filtering the resulting suspensions. The filtrates were analyzed by ESI-MS and analytical HPLC to determine the degree of digestion relative to non-treated controls.

Binding affinities of cyclic peptides at the somatostatin and urotensin receptors were determined by radioligand displacement assays by MDS Pharma Services (Taiwan). $\mathrm{CHO}$ cells expressing recombinant hUT or hSST receptors and radio-labeled somatostatin and urotensin were employed in these experiments. Funtional agonism was determined by the rat thoracic artery assay, also by MDS Pharma Services. All thermodynamic experiments were performed in triplicate. 